\title{
THE MOTIVATIONS TO STUDY OF UNDERGRADUATE STUDENTS IN MANAGEMENT: THE IMPACT OF DEGREE PROGRAMME AND LEVEL OF STUDY
}

\section{Dr Andy Adcroft (University of Surrey)}

Dr Andy Adcroft

School of Management

University of Surrey

Guildford

Surrey

GU2 7XH

E-mail: $\quad$ a.adcroft@surrey.ac.uk

Tel: $\quad 01483682007$

Fax: $\quad 01483685119$

Andy Adcroft is a Senior Lecturer in the School of Management at the University of Surrey where he teaches and researches in the area of strategy. $\mathrm{He}$ is also a Faculty Scholar in the University's Centre for Educational and Academic Development. 


\section{THE MOTIVATIONS TO STUDY OF UNDERGRADUATE STUDENTS IN MANAGEMENT: THE IMPACT OF DEGREE PROGRAMME AND LEVEL OF STUDY}

\section{$\underline{\text { ABSTRACT }}$}

The purpose of this paper is to examine whether there are differences in the type and level of motivation to study between students on specialist and generalist undergraduate degree programmes and between students at different stages of their degree programmes. An adapted scale was used from Pintrich et al's (1991) Motivated Strategies for Learning Questionnaire to measure the Intrinsic and Extrinsic Goal Orientation of undergraduate students in the School of Management at the University of Surrey. 346 completed responses were gathered from students at all levels of study and on different degree programmes. The study suggests that there are significant differences in intrinsic motivation between students on generalist and specialist degree programmes but that there are no significant differences in extrinsic motivation. In terms of level of study, the results suggest that as students progress from first to final year, there are changes to both intrinsic and extrinsic motivation. The findings also suggest that work experience can have a significant effect on motivations to study.

Keywords: Motivation to study, intrinsic motivation, extrinsic motivation, specialist and generalist programmes, levels of study 


\section{INTRODUCTION}

Entwistle (2003) reported a conceptual framework which identified a variety of factors which influence the quality of a university student's learning experience. This framework identifies two broad influences. First are influences attributable to teachers such as the design of a teaching and learning environment and the development of course materials. The second set of influences are those attributable to the attitudes and behaviours of students. These characteristics include, for example, "existing knowledge", "styles of learning", "abilities" and "motives" (p.1). This is reinforced by Cole et al (2004) who argue that motivation is an important issue for research into all levels of education because it is one of the crucial determinants of the success of any learning activity. This point is reinforced by Breen \& Lindsay (2002) who see academic performance as being grounded in motivation and ability and suggest that this lies at the heart of much research in the area which attempts to "find motivational constructs that predict student success" (p.693). The outcome of this, according to Lucas \& Meyer (2005), is that students bring different expectations, learning strategies and learning skills to their studies and this frequently manifests itself in different types of learning. For example, students with high levels of extrinsic motivation will tend to focus on surface learning compared to students with high levels of intrinsic motivation who have a desire to understand. For Lucas \& Meyer (2005), what is crucial in understanding the outcomes of learning is an understanding of why individuals want to learn in the first place.

There is a significant body of literature which examines how motivations to study impact on the experiences of students in higher education. For example, Kong et al (2003) explore this issue in terms of engagement with curricula and suggest that the cognitive, behavioural and emotional engagement of students with their studies is frequently determined by the students' motivation to study. The importance of motivation to the experience of students is further explored by Henderson-King \& Smith (2006) who discuss it in the wider context of the "meaning" of education. They suggest that each student will have a unique motivation to study and this is important because "the degree to which individuals are intrinsically or extrinsically motivated to engage in academic work should have some bearing on their approach to education contexts" ( $\mathrm{p}$.198). This relationship between outcome and purpose is examined in detail by Ponton et al (2005) in the context of "agency" (p.82) and the different actions which result from different types of motivation. Overall, therefore, motivation is a crucial issue for research because it influences the "decision making processes determining the direction, focus and level of effort individuals will apply to a learning activity" (Cole et al, 2004, p.67).

Massingham \& Herrington (2006) suggest that there have been a number of significant changes to the motivations to study of students over the past three decades. They identify a number of studies carried out in the 1970s which suggested that the key motivations for students were based around issues such as "intellectual discovery", a "desire for knowledge" and "enthusiasm" (p.3) and argue that, for a number of reasons, this type of motivation is being 
eroded and replaced by more instrumental motivations whereby education has become "a means towards some end, rather than being valuable in its own right" (p.3). This is a reasonable reflection of a broad cross section of the literature which examines the long term changes in higher education and their impact on traditional views of academia (see, for example, Adcroft \& Willis, 2005).

This paper aims to answer two broad questions. The first question is based around choices of degree programme and whether there are significant differences in types and levels of motivation between students studying generalist degree programmes and more specialist degree programmes. The second question considers the relationship between a student's motivation to study and their stage of study; Is the level and type of motivation to study different between students at different stages of their degree programmes? The paper will next provide some theoretical underpinning to the examination of motivation to study followed by an explanation of the methodological approach taken to data collection before presenting the results of that data collection. The paper considers some of the academic and practical implications of the data before drawing conclusions and making some suggestions for future research in this area.

\section{LITERATURE REVIEW}

In measuring the motivations to study of undergraduate students, this paper begins with the assumption that motivation is an important influence on student learning. Entwistle (2003) argues that motivation is one of a number of characteristics which influences how students approach their learning and studying and how they perceive the environment in which they learn. In doing this, the paper considers motivation across two dimensions: Intrinsic motivation and extrinsic motivation. Fagan et al (2008) suggest that intrinsic motivation "refers to doing something because it is inherently interesting or enjoyable" (p.31) which is a common explanation across much of the literature. For example, Walker (2008) discusses it in terms of the satisfaction gained from "the activity itself" (p.290) and Patall et al (2008) explain it as a willingness to engage in an activity "for its own sake" (p.271). Whilst the broad concept is relatively simple to define, the constituents of intrinsic motivation are more complex. Deci et al (1999) explain it through the psychological need for "autonomy" (the sense of an individual being in control of their own decision making) and "competence" (being able to demonstrate a certain degree of proficiency in a chosen activity) (p.268). Patall et al (2008) develop this further and raise two important issues. First, the importance of choice as "people are more likely to engage in an activity if they believed they had chosen it". Second, "relatedness" and the placing of an activity into the context of the wider goals and expectations of the individual. The explanation of Shroff et al (2008) will guide this research and focuses on three related components to intrinsic motivation: $A$ readiness to engage in activities because of curiosity, a desire to master that activity and an ability to demonstrate competency in that activity. 
The natural and logical counterpoint to intrinsic motivation is extrinsic motivation. Again there is a common explanation across much of the literature which focuses on the "performance of an activity in order to attain some separable outcome" (Walker, p.290). Fagan et al (2008) take this one step further and argue that there must be an element of "perceived usefulness" (p.33) to activities carried out. This is reinforced by Vallerand et al (1992) who define it as "a wide variety of behaviours which are engaged in as a means to an end and not for their own sake" (p.1006). As with intrinsic motivation, the constituent parts of extrinsic motivation are as important as the broad definition and Ryan \& Deci (2000) summarise a number of studies by suggesting that there are four dimensions to extrinsic motivation: First, "external regulation" where the individual focuses on rewards and/or punishments that may result from undertaking an activity; second, "introjection" where an activity is undertaken in order to secure approval from others; third, "identification" where the individual begins, consciously, to value the activity and, fourth, "integration" where the outcomes of the activity are congruous with the individuals wider goals (p.61).

In discussing the differences in motivation between students at different stages of their studies, Ditcher (2001) examines the issue in the context of engineering undergraduates and concludes that, over time, students take an increasingly "instrumental" approach to their learning which is "marked by a motivation to pass exams ... rather than an interest in learning" (p.25). Husman \& Lens (1999) explain this phenomenon through the importance of goals and argue that motivation to study is essentially driven by the goals of the student. As students progress through their studies they become more focused on their goals and, as a result, intrinsic motivation falls and extrinsic motivation increases. Dolnicar (2005) reinforces this point by looking at the specific issue of lecture attendance across a broad range of subject areas and shows a growing pragmatism among more experienced students whereby lectures are attended to "find out what I am supposed to learn" rather than because the student may "enjoy them" (p.107). Husman et al (2004) draw similar conclusions and suggest a growth in instrumentality as students get closer to the end of their studies. Dolnicar (2005) sums up the position by suggesting that "pragmatism now determines the reality of the education environment" (p.103).

This paper's second point of enquiry, the differences between generalist and specialist students, is examined by Cordova \& Lepper (1996) who discuss the issue across three dimensions; contextualisation, personalisation and choice. Where each of these dimensions is present, Cordova \& Lepper (1996) argue, motivation will be higher. This is reinforced by lyengar \& Lepper (1999) who suggest that the link between high levels of motivation and individuals carrying out actions they have made explicit choices about is "self evident" (p.349). Further evidence is provided by Reeve et al (2003) who have examined the relationship between "self-determination" and motivation and whether individuals feel higher levels of autonomy and motivation if they undertake actions which are the result of their own choices. Reeve et al (2003) studied undergraduate students in education studies and found that 
explicit and proactive choice of study frequently goes hand in hand with high levels of motivation to study.

These two elements of diversity of motivation raise a number of issues as far as teaching and learning are concerned. For example, Breen \& Lindsay (2002) discuss the issue in relation to managing cohorts of students where there are different levels of motivation within the student members. In discussing the relationship between motivated and unmotivated students, they conclude that where there is likely to be influence it will probably have its most powerful effect in dragging down the motivation of students rather than vice versa; "students who lack motivation can demotivate their peers and the academics who teach them" (p.693). Under these conditions, managing motivation is a crucial task for academic staff. For example, Pintrich \& De Groot (1990) suggested that teachers develop "classroom situations and tasks that can foster motivation" (p.33) and Reeve et al (2003) explain the relationship between teaching activities and student motivation as being "mutually supportive" (p.377).

In measuring overall motivation, Ryan \& Deci (2000) suggest that, on an individual by individual basis, it will differ in two ways. First, individuals will have different levels of motivation and, second, individuals will have different orientations to their motivation. In this study an individual's motivation to study is not seen as being either intrinsically or extrinsically driven but rather as a blend of the two. The conceptual challenge in all this is to combine them to provide an overall view of motivation for both individual students and also for cohorts of students. In order to do this, the research uses the approach taken by Adcroft \& Teckman (2008) who examine the relationship between motivation (and other variables) and the outcome of sporting contests. On this basis, two key differences are identified. First, those with high intrinsic motivation will tend to find their motivation through themselves, and, second, they will be focused on the process of the activity. Alternatively, those with a high extrinsic motivation will be more driven by external factors and will focus on outcomes. Figure 1 reflects these issues diagrammatically and offers four main groups to which individuals can belong.

Figure 1: $\quad$ Intrinsic and Extrinsic Goal Orientation Matrix

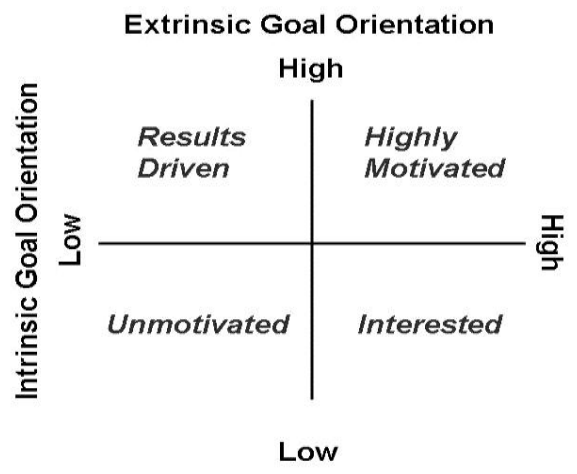


The first group, Highly Motivated, are those individuals who are not only curious about the activity but also want to achieve a clear result from it. The second group, Interested, are those who are less concerned with outcomes and issues external to them but are simply curious about the activity. The third group, Results Driven, are those people who are relatively indifferent about the activity but, nevertheless, want to achieve good results and the final group Unmotivated, are those individuals who are not interested or curious about the activity and are unconcerned with what outcome they may achieve. Dealing with motivations to study in this conceptual manner allows for two important points of analysis. First, it facilitates an understanding of the diversity of motivations within any given cohort of students and, second, it allows for an easy comparison between different cohorts of students which is essential in a comparative paper like this one.

\section{METHODOLOGY}

The sample for this study was drawn from undergraduate students in the School of Management at the University of Surrey. Over 55\% of undergraduate students in the School of Management study for a Bachelor of Science (BSc) degree in Business Management. The BSc in Business Management is a generalist degree programme which requires students to study a broad cross section of subjects. The remaining undergraduate students in the School study on specialist degree programmes which are offered in areas such as tourism, hospitality, retail and accounting and finance. Both specialist and generalist degree programmes are between three and four years in duration. Students on a four year programme undertake a Professional Training Year (PTY) after their second year of study in which they spend a year working in industry. Those on a three year programme progress directly to the final year after their second year of study. The final year of study is the same for students who have and have not undertaken a PTY. Table 1 provides summary details of the responses by level of study and degree programme.

Table 1: $\quad$ Population and Sample Characteristics

\begin{tabular}{|l|c|c|c|}
\hline \multicolumn{1}{|c|}{ Unit of Analysis } & Total Students & Responses & $\begin{array}{c}\text { Response } \\
\text { Rate }\end{array}$ \\
\hline All students & 1275 & 346 & $27.1 \%$ \\
\hline First year students & 507 & 125 & $24.7 \%$ \\
\hline Second year students & 444 & 91 & $20.5 \%$ \\
\hline Final year students & 324 & 130 & $40.1 \%$ \\
\hline Generalist students & 724 & 185 & $25.6 \%$ \\
\hline Specialist students* & 551 & 161 & $29.2 \%$ \\
\hline Students with PTY & 230 & 74 & $32.2 \%$ \\
\hline Students without PTY & 94 & 44 & $46.8 \%$ \\
\hline
\end{tabular}

* Includes degrees in International Hospitality and Tourism Management, International Hospitality Management, Tourism Management, Accounting and Financial Management, Financial Services Management and Retail Management

The method of data collection chosen for this study was primarily determined by the ethical regulations of the University for this type of study. These regulations insist that students are made aware of a clear separation between 
their degree studies and surveys they may participate in. In practical terms this meant that a paper based survey distributed in, for example, large lectures was not possible even though "response rates for web surveys are lower than those for paper and pencil surveys" (Sax et al, 2003, p. 413). The instrument for the study was, therefore, administered on-line and all undergraduate students in the School were invited to participate by e-mail. Reminder e-mails were sent weekly and the survey was kept open for 4 weeks.

In total, 346 fully completed responses were received giving an overall response rate of $27.1 \%$. There is variation in response rate across both levels of study and degree programme. For example, whilst 1 in 4 students in the first year of their studies completed the survey, for second year students the response rate fell to just 1 in 5 . In terms of the response rates from the different programmes, the generalist programme produced a response rate in excess of 1 in 4 students. $66 \%$ of students in the sample on generalist degree programmes undertook a PTY compared to just $58 \%$ on specialist degrees. On specialist degree programmes, there were slightly higher response rates across all programmes. These response rates were disappointing if not surprising. The overall response rate was broadly similar to that of other studies which have looked at similar issues using the same method for data collection. For example, both Breen \& Lindsay (2002) and Walker (2008) examined motivations though on-line data collection and enjoyed response rates of less than 30\%. This is consistent with Sax et al's (2003) study which shows that university students are "responding at lower rates than in previous decades" (p. 411). Nevertheless, the issue of non-response bias still remains and the difficulty for this study is that the usual methods of dealing with nonresponse bias, for example comparisons with known values of the population, are not available: No demographic data such as age, gender or ethnicity was collected on advice from the University's Ethics Committee. The implications of this are two-fold. First, any conclusions drawn from the data must be tentative as generalisability may be an issue and, second, findings of this study need to be examined in relation to findings of previous studies in this area.

In order to measure the blend of intrinsic and extrinsic motivations to study, the paper makes use of two adapted scales from the Motivated Strategies for Learning Questionnaire (MSLQ) developed by Pintrich et al (1991). The MSLQ is a modular instrument whose scales measure a variety of motivations to learn, expectations of learning and learning strategies. Duncan \& McKeachie (2005) have identified over 50 studies between 2000 and 2004 which make use of the MSLQ and, of these studies, almost two-thirds make use of just some (rather than all) of the scales. Given that the purpose of this study is to examine motivations to learn, the two most relevant scales from the MSLQ were used: Intrinsic Goal Orientation and Extrinsic Goal Orientation. Intrinsic Goal Orientation (IGO) measures the degree to which the student is "participating in a task for reasons such as challenge, curiosity, mastery ... participation in the task is an end all to itself" (Pintrich et al, 1991, p.9). Extrinsic Goal Orientation (EGO) measures the degree to which a student is "participating in the task for reasons such as grades, rewards, 
performance, evaluation by others, competition ... engaging in a learning task is a means to an end" (Pintrich et al, 1991, p.10).

Whilst using just two scales from the MSLQ gives the benefit of focus to the data collection, one of the drawbacks is that each scale has just four items. For the purposes of this study, therefore, two additional items were added to each of the scales. These additional items are all adapted from Pintrich \& De Groot's (1990) study of the relationship between motivation and academic performance which was a forerunner to the development of the MSLQ. Table 2 presents the items for each of the scales under discussion.

Table 2: $\quad \underline{\text { Scale Items }}$

\begin{tabular}{|c|c|}
\hline Intrinsic Goal Orientation & Extrinsic Goal Orientation \\
\hline $\begin{array}{l}\text { - On my degree, I want the modules to be } \\
\text { really challenging so that I can learn new } \\
\text { things } \\
\text { - I would prefer course material that } \\
\text { arouses my curiosity even if it is difficult } \\
\text { to learn } \\
\text { I hope to have gained a broader and } \\
\text { deeper knowledge when I have } \\
\text { completed my degree programme } \\
\text { The most satisfying thing on this degree } \\
\text { will be trying to understand the content of } \\
\text { modules as thoroughly as possible } \\
\text { I want to learn as much as possible from } \\
\text { all the modules I study } \\
\text { If I have the opportunity in my degree } \\
\text { studies to choose, I will pick assignments } \\
\text { that I can learn from even if it doesn't } \\
\text { guarantee a good grade }\end{array}$ & $\begin{array}{l}\text { - In my studies, the most important thing is } \\
\text { getting a good degree classification } \\
\text { - It is important to me to be better than } \\
\text { other students } \\
\text { - The most important thing to me right now } \\
\text { is getting good marks in each of the } \\
\text { modules I study } \\
\text { - If possible, I would like to get better } \\
\text { marks than most of the other students } \\
\text { - I am motivated by the thought of } \\
\text { outperforming my peers } \\
\text { I want to do well on this degree because } \\
\text { it is important to show my ability to my } \\
\text { family, friends, employer or other people }\end{array}$ \\
\hline
\end{tabular}

One of the main outcomes of the addition of these items is that the balance of each scale is altered. With the IGO scale, the emphasis is now on the acquisition of knowledge which Massingham \& Herrington (2006) and Shroff (2008), for example, have both identified as being central to intrinsic motivation to study. Similarly, the EGO scale is now more focused on the external comparison dimension to extrinsic motivation which has been identified as important in a number of studies examined by Ryan \& Deci (2000). The final change made in each scale is in the wording of different items so that respondents were asked about their motivation to study across a degree programme rather than just a single module. These changes rightly raise issues in terms of the reliability of the adapted scales. Table 3 presents the Cronbach Alpha score for each of the scales across the different units of analysis for both the reliability of the scale with just the four MSLQ items and with the additional items included. Santos (1999) suggests that " 0.70 is the cut off value for being acceptable" and in each case the addition of the two items increases the Cronbach Alpha score for each scale to an acceptable level. 
Table 3: $\quad$ Cronbach Alpha Scores for Scales Used in the Study

\begin{tabular}{|l|c|c|c|c|}
\hline & \multicolumn{2}{|c|}{$\begin{array}{c}\text { Intrinsic Goal } \\
\text { Orientation }\end{array}$} & \multicolumn{2}{c|}{$\begin{array}{c}\text { Extrinsic Goal } \\
\text { Orientation }\end{array}$} \\
\hline & $\begin{array}{c}\text { with 4 } \\
\text { MSLQ } \\
\text { items }\end{array}$ & $\begin{array}{c}\text { with all } \\
\text { items }\end{array}$ & $\begin{array}{c}\text { with 4 } \\
\text { MSLQ } \\
\text { items }\end{array}$ & $\begin{array}{c}\text { with all } \\
\text { items }\end{array}$ \\
\hline All Students & 0.6829 & 0.7613 & 0.6741 & 0.7781 \\
\hline First Year Students & 0.6308 & 0.7269 & 0.6666 & 0.7424 \\
\hline Second Year Students & 0.7136 & 0.7567 & 0.5831 & 0.7739 \\
\hline Final Year Students & 0.6969 & 0.7772 & 0.7358 & 0.8064 \\
\hline Final Year Students With PTY & 0.7569 & 0.7936 & 0.7973 & 0.8201 \\
\hline Final Year Students Without PTY & 0.6064 & 0.7482 & 0.6157 & 0.7528 \\
\hline Generalist Students & 0.6921 & 0.7613 & 0.6728 & 0.7842 \\
\hline Specialist Students & 0.6599 & 0.7486 & 0.6874 & 0.7817 \\
\hline
\end{tabular}

All questions were in the form of statements and students were asked to rate each statement on a 7 point Likert scale according to how closely the statement reflects their view of themselves. On this scale, 1 signified that the statement was in no way like the student and 7 signified that the statement was a lot like them. In keeping with common practice when using the MSLQ, each respondent was given a score for the two scales which was simply the arithmetic mean of each question answered. In addition to these 12 questions, respondents were also asked for information about their studies, specifically what level of study they had reached, which degree programme they are studying and, for final year students, whether or not they had undertaken a PTY.

\section{FINDINGS}

In order to contextualise the discussion of differences in motivation between students groups, this section of the paper will first consider the relationship between IGO and EGO and, second, present some characteristics of the sample as a whole. Table 4 below presents the results of a basic Pearson's correlation calculation and suggests that, overall, these two elements of motivation are either independent of each other or have limited correlation. Cohen et al (2003) suggest that, in studies of this nature, scores of $0.3-0.1$ and $-0.3--0.1$ can be classified as representing only a small correlation and scores of $-0.1-0.1$ can be classified as being insignificant in terms of correlation. Where there is the highest correlation between IGO and EGO (amongst second year students and some final year students) the correlation coefficient is still low. To a large extent this is to be expected. The MSLQ is a modular instrument where scales can be abstracted without impacting on reliability and validity and this would not be possible if scales were highly correlated. In addition, it adds weight to the conceptual model developed earlier which suggests that motivation is best viewed as a blend of intrinsic and extrinsic motivation rather than as one or the other. 
Table 4: $\quad$ The correlation between IGO and EGO within different student groups

\begin{tabular}{|l|c|}
\hline & Pearson's Correlation Coefficient \\
\hline All students & 0.1122 \\
\hline First year students & 0.1976 \\
\hline Second year students & 0.2781 \\
\hline Final year students & -0.0155 \\
\hline Final year students with PTY & -0.1454 \\
\hline Final year students without PTY & 0.2418 \\
\hline Generalist students & 0.1338 \\
\hline Specialist students & 0.0919 \\
\hline
\end{tabular}

Figure 2 below makes use of that conceptual model and shows the distribution of the whole sample across the four motivation groups. In keeping with common practice when using the MSLQ, the dividing line between a high and low score on each of the scales is the central point on the scales: In using a 7 point Likert scale, respondents who's score above 3.5 are classified as having high IGO or EGO and those who score below 3.5 are classified as having low IGO or EGO. Across the sample, levels of motivation are high; almost two-thirds of all respondents have both high intrinsic and extrinsic motivations to study and, of the remainder, the vast majority of students have either high intrinsic or high extrinsic motivation to study. Only 6\% of the sample have both low intrinsic and extrinsic motivation and can, therefore, be classified as Unmotivated.

Figure 2: Distribution of Total Sample by Motivation Group

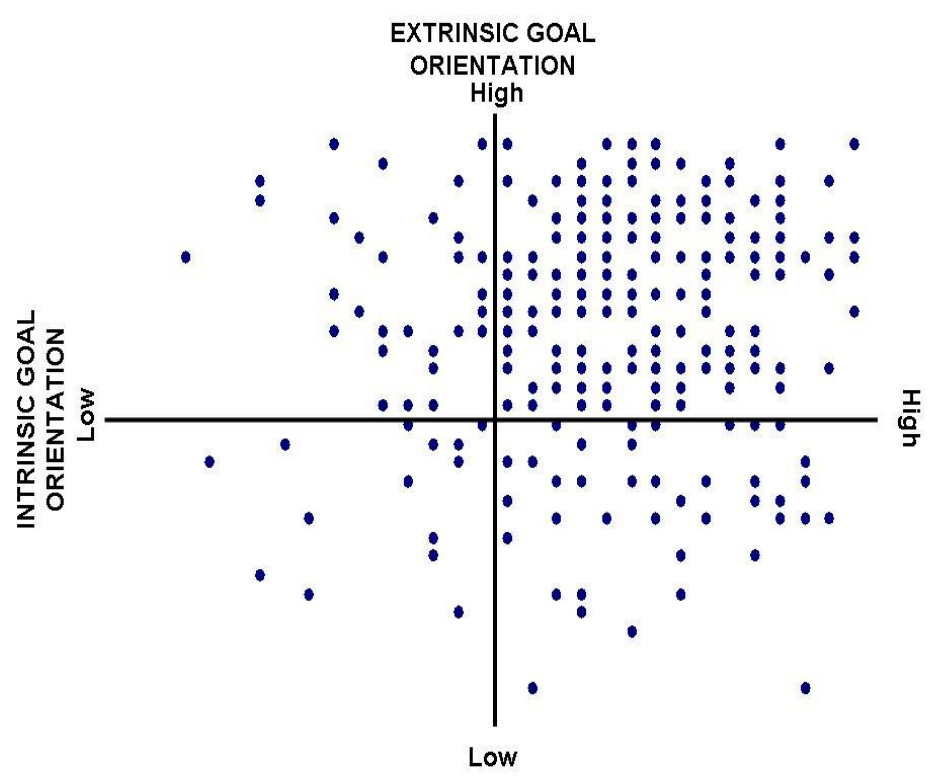

Table 5 presents data across levels of study and degree programme for the four motivation groups. In terms of level of study, the data suggests that the proportion of highly motivated students falls significantly between the first and second year and slightly between the second and final year. The proportion of 
students who are Results Driven also rises by one-third between first and final year. Perhaps of most concern is the higher proportion of Unmotivated students at the end of their studies than at the start. There are also interesting patterns to emerge between generalist and specialist students. The most interesting patterns are in the Interested and Results Driven groups: As a generalisation, students on specialist programmes are more curious about their studies whilst students on generalist programmes are more concerned with the grades they achieve. Nearly three times as many generalist students are Unmotivated than specialist students.

Table 5: $\quad$ Distribution of Sample by Motivation Group (\%)

\begin{tabular}{|l|c|c|c|c|}
\hline \multicolumn{1}{|c|}{ Unit of Analysis } & $\begin{array}{c}\text { Highly } \\
\text { Motivated }\end{array}$ & Interested & $\begin{array}{c}\text { Results } \\
\text { Driven }\end{array}$ & Unmotivated \\
\hline All students & 64 & 17 & 13 & 6 \\
\hline First year students & 72 & 14 & 12 & 2 \\
\hline Second year students & 61 & 21 & 7 & 11 \\
\hline Final year students & 59 & 17 & 18 & 6 \\
\hline Generalist students & 61 & 15 & 16 & 8 \\
\hline Specialist students & 65 & 25 & 7 & 3 \\
\hline
\end{tabular}

The paper now turns to data which focuses on the issue of differences in motivation between student groups. Table 6 presents the results for each of the student groups under discussion. Consistent with the data already presented, students show high levels of both intrinsic and extrinsic goal orientation; on the 7 point scale the lowest mean score across the sample is 5.01 and the highest is 5.52. There are, however, some significant variations across the units of analysis. The results for intrinsic goal orientation show that students at different levels of study have differing levels of curiosity about what they are studying; for example, there is a sharp drop between students in level 2 and level 3 . There are also some interesting differences between level 3 students who have done a PTY and those who have not; students who do not undertake a PTY have higher levels of intrinsic motivation than those who do undertake a PTY. Perhaps the most significant differences in IGO are between students on different programmes; students who study specialist programmes demonstrate higher levels of IGO than students who study on the generalist programme. There are also differences in EGO. For example, there are differences across levels of study although these differences do not follow the neat pattern of IGO. The sharpest fall in extrinsic motivation is between first and second year students but this is followed by higher levels of extrinsic motivation amongst final year students. Again there are differences between final year students who have and have not done a PTY which, in this case, are the opposite of that of IGO. Students who have done a professional training year have significantly higher EGO than other final year students. 
Table 6: $\quad$ Summary Results by Student Groups

\begin{tabular}{|l|c|c|c|c|}
\hline \multirow{2}{*}{} & \multicolumn{2}{|c|}{$\begin{array}{c}\text { Intrinsic Goal } \\
\text { Orientation }\end{array}$} & \multicolumn{2}{c|}{$\begin{array}{c}\text { Extrinsic Goal } \\
\text { Orientation }\end{array}$} \\
\cline { 2 - 5 } & Mean & $\begin{array}{c}\text { Standard } \\
\text { Deviation }\end{array}$ & Mean & $\begin{array}{c}\text { Standard } \\
\text { Deviation }\end{array}$ \\
\hline All students & 5.27 & 0.93 & 5.33 & 1.06 \\
\hline First year students & 5.37 & 0.85 & 5.48 & 0.95 \\
\hline Second year students & 5.34 & 0.88 & 5.09 & 1.07 \\
\hline Final year students & 5.10 & 1.01 & 5.30 & 1.12 \\
\hline Final year students with PTY & 5.01 & 0.97 & 5.46 & 1.10 \\
\hline Final year students without PTY & 5.25 & 1.06 & 5.02 & 1.10 \\
\hline Generalist students & 5.13 & 0.95 & 5.32 & 1.05 \\
\hline Specialist students & 5.41 & 0.90 & 5.36 & 1.07 \\
\hline
\end{tabular}

The paper now turns to consider the significance of these mean scores as presented in Table 6 . The p-values from an ANOVA test suggest that there are, at a minimum of $95 \%$ confidence levels, a number of significant differences between some student groups in terms of both IGO and EGO. Table 7 presents the results of this statistical procedure and shows that there are statistically significant differences in IGO between generalist and specialist students and between second and final year students, especially final year students who have undertaken a PTY. In terms of EGO, there are statistically significant differences between first and second year students and between final year students who have and who have not undertaken a PTY. 
Table 7: $\quad$ Results for Significance of Differences between Student Groups

\begin{tabular}{|r|c|c|}
\hline Mean Generalist Students & $\begin{array}{c}\text { Intrinsic Goal } \\
\text { Orientation }\end{array}$ & $\begin{array}{c}\text { Extrinsic Goal } \\
\text { Orientation }\end{array}$ \\
\hline Mean Specialist Students & 5.13 & 5.41 \\
\hline $\boldsymbol{p}$-value & $\mathbf{0 . 0 1}$ & 5.36 \\
\hline Mean First Year Students & 5.37 & $\mathbf{0 . 8 7}$ \\
\hline Mean Second Year Students & 5.34 & 5.48 \\
\hline p-value & $\mathbf{0 . 7 2}$ & $\mathbf{0 . 0 5}$ \\
\hline Mirst and Second Year students & & \\
\hline Mean Final Year Students & 5.34 & 5.09 \\
\hline pecond and Final Year students & 5.10 & 5.30 \\
\hline Mean Second Year Students & $\mathbf{0 . 0 3}$ & $\mathbf{0 . 4 4}$ \\
\hline $\begin{array}{r}\text { Second Year and Final Year students who have } \\
\text { undertaken a Professional Training Year }\end{array}$ & & \\
\hline Mean Second Year Students & 5.34 & 5.09 \\
\hline Mean Final Year With PTY & 5.01 & 5.46 \\
\hline p-value & $\mathbf{0 . 0 1}$ & $\mathbf{0 . 1 2}$ \\
\hline $\begin{array}{l}\text { Second Year and Final Year students who have not } \\
\text { undertaken a Professional Training Year }\end{array}$ & & \\
\hline Mean Second Year Students & 5.34 & 5.09 \\
\hline Mean Final Year Without PTY & 5.25 & 5.02 \\
\hline $\boldsymbol{p}$-value & $\mathbf{0 . 3 6}$ & $\mathbf{0 . 4 8}$ \\
\hline $\begin{array}{l}\text { Final Year students who have undertaken a } \\
\text { Professional Training Year and Final Year students } \\
\text { who have not undertaken a Professional Training } \\
\text { Year }\end{array}$ & & \\
\hline Mean Final Year With PTY & 5.01 & 5.46 \\
\hline Mean Final Year Without PTY & 5.25 & 5.02 \\
\hline p-value & $\mathbf{0 . 2 1}$ & $\mathbf{0 . 0 4}$ \\
\hline
\end{tabular}

\section{DISCUSSION}

The purpose of this study was to examine whether there were any differences in the motivations to study between students on different degree programmes and between students at different levels of study and in both of these cases a number of differences and similarities have been identified. On the issue of students on different degree programmes, whilst there were no significant differences in extrinsic motivation, students on specialists programmes did show higher levels of intrinsic motivation and there were far fewer unmotivated students as a proportion of the group compared to those students studying for a generalist degree. The are also differences and similarities between students at different stages of their degree programme. For example, second year students showed lower levels of extrinsic motivation compared to first year students and this is broadly reflective of second year students containing proportionately the largest group of unmotivated students. As a counterpoint to this, however, second year students demonstrated higher levels of intrinsic motivation compared to final year students although the differences in extrinsic motivation between these two groups did not pass the $95 \%$ confidence threshold and so are not viewed as significant. One of the more interesting and unexpected findings from the 
study surrounds the importance of the PTY; the differences in intrinsic motivation between second and final year students are most pronounced where students have undertaken a PTY and across final year students, those who have done a PTY have higher levels of extrinsic motivation.

The study, therefore, presents data which both supports and contradicts previous work in this area. For example, the data suggests that whilst it is possible to generate group characteristics through the aggregation of individual responses, it is important to recognise the diversity of motivation within any given cohort. Lucas \& Meyer (2005), Henderson-King \& Smith (2006) and Cole et al (2004) all suggested that this diversity of motivations is important and this point has been illustrated in the paper with the four different motivation groups and the distribution of the sample within them. Similarly, lyengar \& Lepper (1996) and Cordova and Lepper (1996) both suggested that students studying on specialist degrees are likely to have higher levels of intrinsic motivations to study than those on generalist degree programmes because they have made much clearer, explicit and specific choices of what they wish to study. In this study, not only were levels of IGO significantly higher amongst specialist students but so too were the proportion of students classified as either 'highly motivated' or 'interested'. Proportionately, more than twice as many generalist students were 'results driven' or 'unmotivated'. There are, however, some important areas where the results of this study differ to previous studies and this is especially in the area of level of study. Studies discussed earlier by Husman \& Lens (1999), Ditcher (2001) and Dolnicar (2005) all suggested that extrinsic motivation will increase as students get closer to the completion of their degree studies whereas this study suggests something slightly more complicated: In general, final year students are no more extrinsically motivated than second year students but there are some significant differences whereby those students who have undertaken a PTY have higher levels of extrinsic motivation.

There are two significant practical implications of this research. The first concerns student groups with a diverse collection of motivations. Within some groups of students, especially those on generalist programmes and in their second year of study, the diversity is most significant as there is a substantial tail of students who lack both intrinsic and extrinsic motivation to study. This suggests that one sub-group of students may want a richer experience than another. For example, students with high levels of extrinsic and intrinsic motivations to study would probably want feedback that focused on both how they could learn more and how they could get better marks whereas students with just high extrinsic motivation would be satisfied with the latter. There are a number of pedagogical challenges raised in teaching cohorts of students with a diversity of motivations and these challenges are almost inevitable given the design of degree programmes which means that students on generalist and specialist programmes will, at some points, study the same modules. There are issues, for example, in the design of modules, learning outcomes and assessments which will meet the expectations of students whose primary motivation is curiosity and interest as well as meeting the expectations of those students with a more instrumental mindset. This is a major issue for academics in business and management fields who deal with 
large cohorts of students: in the School of Management from which this sample was drawn there are over 550 undergraduates on specialist programmes and over 700 on generalist programmes. The second pedagogical challenge raise by all this focuses on the quality of the student learning experience. If students want to do equally well at the beginning and the end of their studies, how can pedagogical approaches be developed which maintain their interest and curiosity? The extent to which this is possible is beyond the scope of this paper but the basis point should not be lost that these expectations should be understood and, where possible, managed; Breen and Lindsay (2002), Reeve et al (2003) and Pintrich and De Groot (1990) are all, for example, optimistic about the scope for pedagogical interventions which shape the motivations of students.

\section{$\underline{\text { CONCLUSION }}$}

The data presented in this paper is both internally and externally consistent. Internally it is consistent because it presents a clear narrative of motivations to learn across different programmes and levels of study through the use of a conceptual model and statistical tests for reliability, validity, correlation and significance. It is externally consistent because it sits reasonably comfortably with previous research in this area and the narrative is coherent with much other research. There are, however, two obvious limitations with the study. The first limitation is in the data collected which is, to use an analogy, a series of snapshots of student motivation rather than a moving picture of student motivation. This means that the paper can discuss differences in motivation across levels of study but not how the motivations of a particular cohort of students change over time. The weakness of this is that the paper makes assumptions about the typicality (as well as the generalisability) of the student sample but the strength is that it opens up new avenues to investigate with studies over a longer period which do track cohorts of students through their entire studies. The second limitation is that the paper has generated a picture of how students are motivated but not a picture about what motivates them or changes their motivations over time. The obvious implication of this is that it opens up the possibilities of new studies with extended and more complex instruments. The differences in motivation between students who have and have not undertaken a PTY is an unintended outcome of this research which requires further and deeper investigation. For example, is it students with higher levels of extrinsic motivation who choose to undertake work placements or does the experience of work placement contribute to the development of such a motivation?

In 'The West Wing' Jed Bartlett rails against those who only deal in black and white or right and wrong and suggests that there are very few "unnuanced moments". So too is it with the study of motivations. The generalisable outcomes are important and significant but what is often most interesting are the nuances and subtle differences between individuals and cohorts that open up new avenues to investigate: Why do students become less interested in what they are studying over time? How does the diversity of motivation in a cohort influence the experiences of students in that cohort? What pedagogical interventions can be made to manage and shape the expectations of 
students? Regardless of its rigour, the main strength of this paper is in the possibilities it opens up for future research.

\section{$\underline{\text { REFERENCES }}$}

Adcroft, A. and Willis, R. (2005) The (un)Intended Outcome of Performance Measurement in the Public Sector in The International Journal of Public Sector Management Volume 18, Number 5 pp 386-401

Adcroft, A. and Teckman, J. (2008) Theories, Concepts and the Rugby World Cup: Using management to understand sport in Management Decision, Volume 46, Issue 4. pp 600-625

Breen, R. and Lindsay, R. (2002) Different disciplines require different motivations for student success in Research in Higher Education, volume 43, number 6, pp693-725

Cohen, J., Cohen, P., West, S. G. and Aiken, L. S. (2003) Applied multiple regression/correlation analysis for the behavioural sciences (third edition), Lawrence Erlbaum Associates, New Jersey, USA.

Cole, M. S., Feild, H. S. and Harris, S. G. (2004) Student Learning Motivation and Psychological Hardiness: Interactive effects on students' reactions to a management class in Academy of Management Learning and Education, volume 3, number 1, pp64-85

Cordova, D. I. and Lepper, M. R. (1996) Intrinsic motivation and the process of learning: Beneficial effects of contextualisation, personalisation and choice in Journal of Educational Psychology, volume 88, number 4, pp715-730

Deci, E.L., Koestner, R. and Ryan, R.R. (1999) A Meta-Analytic Review of Experiments Examining the Effects of Extrinsic Rewards in Intrinsic Motivation in Psychological Bulletin, volume 125, number 6, pp627-668

Ditcher, A. K. (2001) Effective Teaching and Learning in Higher Education, with Particular Reference to the Undergraduate Education of Professional Engineers in International Journal of Engineering Education, volume 17, number 1, pp24-29

Dolnicar, S. (2005) Should we still lecture or just post examination questions on the web? The nature of the shift towards pragmatism in undergraduate lecture attendance in Quality in Higher Education, volume 11, number 2, pp104-115

Duncan, T.G. and McKeachie, W.J. (2005) The Making of the Motivated Strategies for Learning Questionnaire in Educational Psychologist, volume 40, number 2, pp117-128

Entwistle, N. (March 2003) Concepts and Conceptual Frameworks Underpinning the ETL Project, Occasional Report 3, ETL Project 
Fagan, M.H., Neill, S. and Wooldridge, B.R. (2008) Exploring the Intention to use Computers: An empirical investigation of the role of intrinsic motivation, extrinsic motivation and perceived ease of use in Journal of Computer Information Systems, Spring, pp31-37

Henderson-King, D. and Smith, M. N. (2006) Meanings of education for university students: academic motivation and personal values as predictors in Social Psychology of Education, volume 9, pp195-221

Husman, J. and Lens, W. (1999) The Role of the Future in Student Motivation in Educational Psychologist, volume 34, number 2, pp113-125

Husman, J., Derryberry, W. P., Crowson, H. M. and Lomax, R. (2004) Instrumentality, task value and intrinsic motivation: Making sense of their independent interdependence in Contemporary Educational Psychology, volume 29, pp63-76

lyengar, S. S. and Lepper, M. R. (1999) Rethinking the value of choice: A cultural perspective on intrinsic motivation in Journal of Personality and Social Psychology, volume 76, number 3, pp349-366

Kong, Q-P., Wong, N-Y. and Lam, C-C. (2003) Student Engagement in Mathematics: Development of Instrument and Validation of Construct in Mathematics Education Research Journal, volume 15, number 1, pp4-21

Lucas, U. and Meyer, J. H. F. (2005) 'Towards a mapping of the student world': the identification of variations in students conceptions of, and motivations to learn, introductory accounting in The British Accounting Review, volume 37, pp177-204

Massingham, P. and Herrington, T. (2006) Does Attendance Matter? An examination of student attitudes, participation, performance and attendance in Journal of University Teaching and Learning Practice, volume 3, issue 2, pp141

Patall, E.A., Cooper, H. and Robinson, J.C. (2008) The Effects of Choice on Intrinsic Motivation and Related Outcomes: A Meta-Analysis of Research Findings in Psychological Bulletin, volume 134, number 2, pp270-300

Pintrich, P. R. and De Groot, E. V. (1990) Motivational and Self-Regulated Learning Components of Classroom Academic Performance in Journal of Educational Psychology, volume 82, number 1, pp33-40

Pintrich, P. R., Smith, D. A. F., Garcia, T. and McKeachie, W. J. (1991) A Manual for the Use of the Motivated Strategies for Learning Questionnaire (MSLQ), Technical Report Number 91-B-004, The University of Michigan, USA.

Ponton, M., Derrick, M. G., Confessore, G. and Rhea, N. (2005) The role of 
self-efficacy in autonomous learning in International Journal of Self-directed Learning, volume 2, number 2, pp81-90

Reeve, J., Nix, G. and Hamm, D. (2003) Testing models of the experience of self-determination in intrinsic motivation and the conundrum of choice in Journal of Educational Psychology, volume 2, pp375-392

Ryan, R.M. and Deci, E.L. (2000) Intrinsic and Extrinsic Motivations: Classic Definitions and New Directions in Contemporary Educational Psychology, volume 25, pp54-67

Santos, J. R. A. (1999) Cronbach's Alpha: A tool for assessing the reliability of scales in Journal of Extension, volume 37, number 2.

Sax, L.J., Gilmartin, S.K. and Bryant, A.N. (2003) Assessing response rates and nonresponse bias in web and paper surveys in Research in Higher Education, volume 44, number 4, pp409-432.

Shroff, R.H., Vogel, D.R. and Coombes, J. (2008) Assessing Individual-level Factors Supporting Student Intrinsic Motivation in Online Discussions: A qualitative study in Journal of Information Systems Education, volume 19, number 1 , pp111-125

Vallerand, R.J., Pelletier, L.G., Blais, M.R., Briere, N.M. Senecal, C. and Vallieres, E.F. (1992) The Academic Motivation Scale: A measure of intrinsic, extrinsic and amotivation in education in Educational and Psychological Measurement, volume 52, pp1003-1017

Walker, G.J. (2008) The Effects of Ethnicity and Gender on Facilitating Intrinsic Motivation during Leisure with a Close Friend in Journal of Leisure Research, volume 40, number 2, pp290-311 